\title{
Prehospital Telemedical Emergency Management of Severely Injured Trauma Patients
}

\section{A Systematic Review}

\author{
Patrick A. Eder ${ }^{1}$ \\ Asarnusch Rashid ${ }^{1}$ \\ ${ }^{1}$ Zentrum für Telemedizin Bad Kissingen, Bad Kissingen, Germany \\ 2 Faculty of Health Safety Society, Furtwangen University \\ Furtwangen, Germany \\ ${ }^{3}$ Department of Anaesthesiology, Section of Emergency and Disaster \\ Medicine, University Hospital Würzburg, Würzburg, Germany \\ ${ }^{4}$ Bavarian Red Cross, Munich, Germany \\ Methods Inf Med 2018;57:e1.
}

\section{Retraction Notice}

The publisher regrets an error that the above article was published online with an incorrect open access CC BY-NC-ND license.
Address for correspondence Patrick Andreas Eder, Zentrum für Telemedizin Bad Kissingen, Sieboldstraße 7, 97688 Bad Kissingen, Germany (e-mail: eder@ztm-badkissingen.de).

For this reason, the article has been retracted and the correct version of the article can be found here: https://doi. org/10.1055/s-0039-1681089. 